\title{
ANÁLISIS DEL DISCURSO AUTOFICCIONAL EN LOS ADOLESCENTES: LA SUBJETIVIDAD A TRAVÉS DEL DIARIO
}

\section{AUTOFICTIONAL DISCOURSE ANALYSIS IN TEENAGERS: SUBJECTIVITY THROUGH DIARY}

\section{Verónica FRANCO GONZÁLEZ \\ Universidad de Zaragoza veronicafranco@unizar.es}

Resumen: El presente estudio ofrece las claves para comprender el discurso del diario personal de los adolescentes mediante el análisis del léxico disponible que estos emplean en su escritura. A partir de la observación de la connotación de estas voces, se pueden extraer conclusiones pertinentes acerca de la consideración del yo autor del diario en relación con su subjetividad; esto es, con respecto a su personalidad, autoconcepto o estado de ánimo, cuestiones que están íntimamente ligadas al desarrollo personal de la adolescencia.

Palabras clave: análisis del discurso, adolescencia, diario, subjetividad, autoficción.

Abstract: The present study offers the key to understand the teenagers' diary discourse by the analysis of the available lexicon that they use in their diary writing. Based on the observation of the connotation of those words, we can infer pertinent conclusions about the consideration of the firstperson narrator related to their subjectivity; that is, regarding their personality, self-concept or mood, issues intimately bound to the personal development of adolescence.

Keywords: discourse analysis, adolescence, diary, subjectivity, autofiction. 
"Ouvrir un journal, c'est comme entrer brusquement dans une chambre obscure, il faut laisser à l'oeil le temps de s'habituer, pour voir peu à peu se révéler dans l'ombre les contours secrets d'une vie humaine»

Philippe Lejeune (2003: 209)

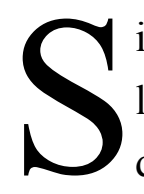
i hemos de atribuir el rasgo de subjetividad a algún subgénero de carácter literario, ese es, sin lugar a dudas, el diario íntimo. No hay nada más significativo que su propia denominación para despejar cualquier atisbo de duda acerca de la conexión entre ambos conceptos. Lo íntimo y lo subjetivo van necesariamente unidos en tanto en cuanto se trata de cualidades atribuibles a la proyección del yo a través de la narración.

En las siguientes páginas se indaga y profundiza en el empleo que los jóvenes hacen del lenguaje en tono autobiográfico e intimista a través de la escritura del diario personal, ámbito en el que se van a analizar los usos de carácter léxico y discursivo en un sentido amplio. La investigación se ha llevado a cabo entre dos grupos de adolescentes de entre 12 y 15 años, haciendo hincapié en los campos semánticos relacionados con la identidad y la subjetividad. Se analiza la escritura autoficcional a través de la propia creación de textos pertenecientes al género del diario íntimo ${ }^{1}$. El objetivo del análisis que aquí se presenta es realizar una valoración del sentimiento de identidad y pertenencia de los adolescentes, puesto que es inherente al ser humano adquirir su identidad personal al sentir que se pertenece a un grupo de referencia y este hecho, debido a la estrecha vinculación entre el modo de comunicarnos y nuestra concepción del yo, genera lingüísticamente una serie de marcas características de dicho grupo. La investigación llevada a cabo en este sentido refleja, a partir de datos lingüísticos concretos que se aprecian en sus propios textos, cómo utilizan los adolescentes los campos léxicos relacionados con los sentimientos y emociones así como el tipo de narrador que aparece; si realizan una escritura elaborada con rasgos casi literarios o se aprecia el uso de un léxico escogido y planificado; o si, por el contrario, el lenguaje es espontáneo y coloquial, con uso de marcadores discursivos de carácter informal, onomatopeyas, etc.

\section{Marco de la investigación}

El marco en el que se desarrolla la investigación es el análisis del discurso autoficcional en los adolescentes como un reflejo de su propia identidad como colectivo.

A través de la escritura creamos y recreamos nuestra identidad. Podemos considerar que nuestra forma de hablar y escribir es producto del yo, esto es, la identidad es algo que fabricamos, inventamos

\footnotetext{
${ }^{1}$ El presente artículo recoge las conclusiones extraídas de un trabajo de investigación desarrollado en la Universidad de Zaragoza durante los estudios del Máster en Profesorado de Educación Secundaria, especialidad de Lengua Castellana y Literatura (2011) y se enmarca en la línea de investigación denominada Sociopoética de la identidad: análisis del discurso autoficcional en el lenguaje de los adolescentes. El proyecto original lleva por título: Análisis del discurso autoficcional en los adolescentes desde el punto de vista sociolingüístico, a través del estudio de los rasgos lingüisticos más significativos. El desarrollo de esta investigación tuvo lugar durante la realización de los Prácticum II y III del máster en el IES Luis Buñuel de Zaragoza, habiendo recibido la tutorización de Da Elvira Luengo Gascón, por parte de la Universidad de Zaragoza, y de $\mathrm{D}^{\mathrm{a}}$ Isabel Abanto, por parte de dicho instituto.
} 


\section{Tropelías. Revista de Teoría de la Literatura y Literatura Comparada, 31 (2019) \\ Análisis del discurso autoficcional en los adolescentes: la subjetividad a través del diario}

99

y construimos a partir de todo aquello que leemos y escribimos. Igualmente, la distancia que nos proporciona la escritura favorece que tomemos conciencia de quiénes y cómo somos.

Escribir nos ayuda a desahogarnos, a expresar nuestros sentimientos y a manifestar nuestros deseos y miedos más íntimos. Y todo eso es lo que somos realmente, lo que conforma nuestra identidad personal, y esta identidad se va a forjar durante los años de la adolescencia, en los que se enmarcan los dos grupos de alumnos seleccionados para la muestra. Por ello, resulta relevante estudiar la identidad del adolescente, en este caso a través de su propia escritura a partir del análisis de los rasgos lingüísticos (gramaticales, léxicos, pragmáticos) que utiliza el alumno, puesto que los estudiantes de Secundaria se encuentran en un momento en el que están construyendo su propia identidad, su personalidad y están, al mismo tiempo, experimentando numerosos cambios físicos e intelectuales.

La adolescencia es la transición progresiva del ser humano desde la infancia hasta la edad adulta. Durante este periodo, de duración variable, surgen algunas características en el individuo que facilitan el progresivo acceso a la autonomía personal y social; así, se posibilita una reconstrucción de la propia identidad personal (revisión de la imagen física, revisión del autoconcepto y la autoestima, revisión de las aspiraciones individuales). El adolescente va forjando poco a poco su futura identidad individual como adulto a través de las relaciones sociales, de su desarrollo intelectual y de la capacidad de juicio.

La vida afectiva en la etapa de la adolescencia se afirma mediante la conquista de la personalidad y de su inserción en la sociedad adulta. Esta personalidad se construye precisamente en este momento, cuando se cumplen determinadas condiciones intelectuales, como el desarrollo y adquisición del pensamiento formal o hipotético-deductivo (Piaget, 1990: 91).

La construcción de esa identidad del adolescente va unida al concepto de la subjetividad, que encuentra en el diario íntimo el marco narrativo más propicio para su expresión lingüística. Vygotsky (1995, cit. en Fernández 2007) plantea que:

El lenguaje tiene una función reguladora que primero es externa y que se internaliza posteriormente. Así, el habla interior es el vehículo de nuestra identidad y permite la continuidad del yo en la vida cotidiana y de un lenguaje externo, social, que es la manifestación del pensamiento en palabras. El pensamiento no se expresa simplemente en palabras, sino que existe a través de ellas, aprendidas socialmente.

Esa internalización del lenguaje a la que hace referencia Vygotsky se expresa y se externaliza a través del diario en primera persona como una muestra de identidad y de expresión del yo que nosotros mismos construimos desde la adolescencia a través de un constante diálogo con la sociedad que se va actualizando y reestructurando permanentemente y que manifiesta una forma de ver el mundo de forma individual y subjetiva.

En este sentido, la subjetividad tiene una función identitaria (Torres, 2006: 42), ya que aporta constructos desde donde los sujetos son capaces de construir su identidad y pertenencia a una sociedad, en concreto, al grupo de los adolescentes. Esa subjetividad se manifiesta a través de representaciones simbólicas culturales, sentimientos e ideologías que sirven para construir marcas singulares del yo como perteneciente a un grupo social particular. La subjetividad requiere un carácter reflexivo en que el sujeto «se plantee una capacidad liberadora consigo mismo» (2006: 43). 
Esta subjetividad (2006: 71):

Alude al proceso de subjetivación, referida al hecho estructurante de que por la mediación de otro se hace posible ser uno, es decir, hablar, juzgar, desear, vivir la vida de una manera propia, y así pertenecer al lazo social y recrearlo. La subjetivación de las experiencias permite argumentar que la identificación parte de vivencias pasadas y presentes.

Desde el punto de vista de Lacan (cit. en Gómez y Carrasco, 2012: 71), la implicación subjetiva que tiene esa necesidad de pertenencia social a un grupo hace de la identidad una dimensión de alienación y desalienación debido a que la identificación siempre está ligada con el deseo del otro. Esto es lo que convierte la percepción supuestamente subjetiva del adolescente en una visión que es en realidad compartida por todo el colectivo de jóvenes como un sentir enciclopédico, que nos recuerda al conocimiento del mundo compartido por los individuos que pertenecen a una misma cultura o sociedad.

La relevancia de la redacción del diario y su interés a nivel discursivo en relación con la expresión de la subjetividad radica en que la adolescencia, una etapa vital en la que se está llevando a cabo la construcción del yo, cuestiona el yo actual y proyecta el yo ideal o deseado de manera permanente en todas las situaciones cotidianas, lo que se refleja, como consecuencia, en la escritura del diario íntimo, donde el joven trata de reconstruir su mundo interior y sus vínculos con el mundo exterior a través de su lucha por la búsqueda de identidad. Y ambos mundos, vistos desde el punto de vista de esa primera persona, se muestran desde una perspectiva subjetiva y sesgada.

En el diario íntimo el narrador habla en primera persona sobre vivencias personales plasmando en su forma de escribir su subjetividad donde el tema de la narración es el sujeto del discurso, un yo íntimo en busca de su propia identidad. Ese yo, esa reiterada referencia deíctica en los textos al autor del diario, se impone como el marcador intrínseco del aspecto de la subjetividad en la narración. Como anota Cortés (2017: 31):

Este tipo de texto subyace, entonces, a la interpretación cognitiva, reflexiva y pragmática de ser y estar en el mundo, en donde el narrador no es un informador de un relato, sino un constructor y fabricante activo de sí a través de la producción de una historia de memoria en donde se recrea retrospectivamente el sí mismo y donde se da un lugar, tanto en la percepción escritural, como en la imagen de sí o percepción subjetiva.

\section{Descripción de la investigación}

El propósito de la investigación consistió en analizar los rasgos de identidad juvenil a partir del léxico y otros rasgos lingüístico-comunicativos que los adolescentes de $1 .^{\circ}$ y $3 .^{\circ}$ de ESO de un instituto de Zaragoza ofrecieron en los diarios íntimos que ellos mismos escribieron a lo largo de varias semanas. Dicho análisis, de carácter sociolingüístico, sirvió para describir las preferencias y usos léxicos de los adolescentes a través de una selección de datos significativos. La metodología utilizada fue de tipo cuantitativo y cualitativo, mediante diversos instrumentos (encuestas, entrevistas y observación en el aula), se recabó información para contrastar el corpus de textos escritos por alumnos de ambos cursos, con edades comprendidas entre los 12 y los 15 años, que tienen unas características 
propias se hallan inmersos en un contexto específico y cuentan con variedad de intereses y motivaciones.

A partir del análisis de estos diarios hemos podido extraer conclusiones de carácter lingüístico que eventualmente son el reflejo de la identidad y subjetividad en los adolescentes, como se detallará más adelante.

\section{Estado del arte}

La bibliografía en torno al género autobiográfico ha aumentado considerablemente durante los últimos años. Así, podemos encontrar numerosas referencias recientes en torno a dicho género que tratan de ofrecer una respuesta más o menos clara acerca de sus características y definición, lo cual no resulta tarea fácil puesto que su clasificación como género literario es más o menos reciente.

Podemos situar en Francia uno de los centros relevantes de investigación acerca de la autobiografía. Philippe Lejeune ha sido el estudioso que más títulos ha dedicado a la investigación de este género. Pero, la escritura del diario personal o íntimo, ¿constituye en sí misma un género?, ¿podemos situarla como un subgénero dentro de la autobiografía? Los estudios de Lejeune afirman que existen diferencias entre ambos términos o géneros, por lo que el diario se situaría como algo distinto a la autobiografía. Si bien este autor define la autobiografía como un «relato retrospectivo en prosa que una persona real hace de su propia existencia, poniendo énfasis en su vida individual y, en particular, en la historia de su personalidad» (Lejeune, 1975: 48), considera, por otro lado, que se diferencia, en algunos de sus rasgos fundamentales del diario íntimo. La diferencia fundamental entre ambos tipos textuales es la posición del narrador, que se sitúa desde una visión retrospectiva en la autobiografía pero no así en el diario personal, en el que el momento de la escritura se sitúa en el mismo espacio temporal en el que se han sucedido los acontecimientos, esto es, al finalizar cada día, en el presente.

Además de la citada obra de 1975, Le pacte autobiographique, otros títulos de Lejeune en los que se trata esta temática son L'autobiographie en France (1971), Pour l'autobiographie (1998), Moi aussi (1986) y, más concretamente sobre el diario íntimo, La Pratique du journal personnel (1990) o Un journal à soi. Histoire d'une pratique (2003), lo que demuestra lo prolífico que es este autor en torno al género autobiográfico y el diario, y lo proyecta como uno de los mayores exponentes en su estudio.

A pesar de que la base teórica de la investigación se fundamenta en los estudios de Lejeune, resultan muy interesantes otros trabajos como La escritura invisible, de Manuel Alberca Serrano (2000); Le journal intime, de Béatrice Didier (1976); o Le journal intime en Espagne, de Danielle Corrado (2000). Todos ellos tratan de sintetizar y presentar los rasgos más significativos de la escritura del diario personal, abarcando las diferentes formas y estructuras que puede presentar y poniendo de manifiesto la dificultad de concretar y definir este género.

En este sentido, si bien el diario íntimo en la literatura ha suscitado ciertos debates a este respecto en la bibliografía reciente, su interés dentro del ámbito de la educación ha disminuido en muchos casos: 
el diario como género apenas es mencionado ni trabajado en las escuelas. El mismo Philippe Lejeune, especialista, en su estudio comenta en uno de sus trabajos: «Les journaux sont rarement étudiés en classe. De toute ma scolarité, je ne me souviens pas d'avoir jamais eu à expliquer un fragment de journal» (Lejeune, 1975: 25).

Hablamos de diario íntimo por su valor de referencia a una práctica particular e individual de escritura del yo, que se centra en la persona del redactor en su dimensión cotidiana (Corrado, 2000: 297). El diario refleja, pero sobre todo crea, la intimidad porque reclama un tiempo de soledad, distanciándose del ruido del mundo; sobrepasa lo social y garantiza la total libertad del alma en el curso de la redacción (Corrado, 2000: 303).

El diario es un lugar seguro, el refugio contra el resto del universo, contra el vacío, el vértigo que amenaza con arrollarnos, contra el salto hacia lo desconocido, la multiplicidad, la dispersión. La intimidad conquistada es «la intimidad uterina y maternal reencontrada gracias a un segundo nacimiento que permite el autoanálisis, la anamnesia y el recurso a la escritura para traducir el discurso» (Didier, 1976: 91).

El mundo interior de cada uno de nosotros es lo que el diario nos permite descubrir y desarrollar; supone un reencuentro, la unidad, el bien. El diario es el lugar donde se escribe la soledad, entendida no como ausencia sino como refugio. El regreso a sí mismo permite «encontrar un centro, descubrir su peso, sus pies, su masa y, por consiguiente, su equilibrio, su anclaje» (1976: 89).

La escritura misma del diario es recordatoria. El diario, reconstruyendo la vida día a día, permite la vuelta atrás: el autor relee lo que ha escrito el mismo día o incluso un año antes. Por otra parte, el diario es para sí mismo un hábito que tiene su principio mismo en la regularidad. El modo de escritura del diario se corresponde perfectamente con la tendencia del diarista del ir y volver, recordar, rememorar: hay una adecuación perfecta del significante y del significado, del sistema de escritura y su objeto (1976: 94). La escritura del diarista aficionado no debe atender a editores ni público, por lo que puede crear su texto como quiera. Fotos, objetos, dibujos, etc., se pueden integrar también en el diario, sobre todo si tienen un valor recordatorio; todo lo que resulte relevante para el yo, que tenga una significatividad para el autor, lo que no deja de ser una cuestión personal, íntima, subjetiva.

Encerrado, protegido en esa prisión matricial del diario, el escritor va a intentar constituirse en tanto que unidad, en tanto que yo. Quiere salir de la indeterminación para ser verdaderamente. Pero el diario es un falso espejo; la imagen que nos devuelve es deformada, falsificada. Es por ello que, según afirma Didier, el diarista se transforma en dos o en múltiples individuos o personalidades. Ese desdoblamiento de personalidad es el fenómeno más extendido y universal constatado por los autores del diario, como demuestran Didier o Lejeune, pero toma formas muy diversas. El diarista es, al mismo tiempo, dos individuos: el que actúa y el que se observa actuar; el que escribe y el que relee (1976: 117), que protagoniza pero que es también quien reorganiza los hechos, quien elige cómo contarlos y los muestra a través de una perspectiva cercana pero bajo una pequeña reflexión personal.

La escritura del diarista queda así consagrada a la expresión, a la creación de sí mismo; muestra todas las búsquedas que le ofrece el espacio temporal que se encuentra a su disposición: un juego de 
pronombres, de tiempos, de ritmo de la frase; un discurso introspectivo, con empleo de la repetición, etc. Los recursos lingüísticos y extralingüísticos que explota el escritor del diario podrían indicar una búsqueda, al igual que de su personalidad, de los límites del género (1976: 186).

Por una parte, la autobiografía se diferencia del diario íntimo en algunos aspectos significativos. La autobiografía es sobre todo un relato retrospectivo y global que tiende a la síntesis y que se escribe con relativa posterioridad a los hechos sucedidos en el pasado, una vez se toma cierta perspectiva que permite añadir un análisis personal y una mayor objetividad, mientras que el diario íntimo es una escritura cuasi contemporánea que no tiene una forma fija. Son dos formas opuestas de escritura íntima pero pueden ser complementarias al mismo tiempo (Lejeune, 1971: 24). Parece relacionarse cada una de estas formas con un tipo de personalidad y momento vital: mientras que puede haber una cierta verosimilitud en el diario íntimo, practicado durante un periodo de tiempo, la autobiografía se escribe durante la madurez y puede oponerse a la personalidad más intimista del diario.

Por otra parte, la autobiografía y el diario íntimo tienen dos puntos de contacto posibles: la autobiografía puede organizar su relato de manera que aparezca el tiempo de la escritura paralelamente al tiempo de la historia contada; la autobiografía puede tratar de hacer revivir el pasado insertando fragmentos del diario íntimo utilizado en ese momento (Lejeune, 1971: 25).

Pero el diario puede recordarnos a otras formas y géneros. Por ejemplo, puede coincidir con algunos aspectos del género epistolar en tanto en cuanto se narra en primera persona y se cuentan hechos de la vida personal del autor. Frente a esto, se distinguen en que, a pesar de que se trata de intercambios comunicativos, hay diferencias en la naturaleza de la relación que se establece con el otro puesto que, en el caso del diario, se narran acontecimientos pero el destinatario es uno mismo o un destinatario inexistente al que se dirigen unas palabras que lo único que tratan es de comunicar en el sentido de desahogarse, compartiendo unas experiencias que nadie, en definitiva, salvo uno mismo excepcionalmente, va a leer. Ambos géneros tienen en común una ausencia de límites, la fragmentación, el día a día, el hecho de conocerse a sí mismo, y no tienen (en principio) valor como producto comercial (Didier, 1976: 194).

Philippe Lejeune, como hemos anotado anteriormente, ha sido uno de los estudiosos que más páginas ha dedicado a escribir acerca del diario íntimo, y en Un journal à soi (2003) recopiló el trabajo de toda una vida dedicada al diario, donde se recogen algunas cuestiones interesantes sobre este género que se van a comentar a continuación.

En primer lugar, Lejeune se plantea quién escribe un diario. Llega a la conclusión de que la escritura del diario suele ser, en general, un fenómeno pasajero, fruto de una crisis o una fase de la vida. Es por ello que podemos asociar la escritura del diario íntimo a la adolescencia, un momento de búsqueda de una identidad propia, de definirnos como personas y de sentar las bases de nuestra personalidad. La identidad en este periodo, como afirma el autor, «está por conquistar» (1998: 16) y se asocia el fenómeno de la escritura del diario a la adolescencia por otro motivo: la escolarización de este grupo social, acostumbrado, además, a tomar apuntes, escribir en cuadernos, tomar notas, etc. En la actualidad, a esto se podría añadir la forma en que se desarrollan las relaciones sociales que se llevan 
a cabo en la escuela y que evolucionan después a través de aplicaciones y redes sociales en las que los jóvenes cuentan también su día a día, sus sentimientos a partir de ciertos acontecimientos sucedidos, de forma similar a la del diario íntimo.

Lejeune se plantea a qué edad se comienza a escribir un diario, concluyendo que entre los $10 \mathrm{y}$ 11 años (2003: 134), sobre todo por parte de las chicas. En la adolescencia o preadolescencia, sobre todo cuando ocurre algún problema de tipo familiar, en la escuela, o con los amigos, es frecuente que comience a escribirse el diario personal. Como dice Philippe Lejeune, «l'adolescence est le pays du journal» (2003: 138).

La práctica del diario decrece conforme avanza la edad, siendo la adolescencia la etapa más propicia para comenzar su escritura, sobre todo en el caso de las chicas. Entre los 11 y los 14 años, afirma Lejeune, el porcentaje de chicas que escriben diarios es mucho mayor al de los chicos, y añade: «à cet âge, le journal est pour les filles une culture de groupe et un rite d'initiation, alors que la plupart des garçons y sont indifférents ou hostiles» (2003: 8).

La investigación llevada a cabo en este campo nos ha permitido corroborar esta idea inicial de Lejeune, puesto que los resultados variaron considerablemente entre las mujeres y los hombres respecto a la escritura del diario y a la concepción de este como un instrumento positivo para conocerse a sí mismos. La mayor afición de las mujeres por la escritura del diario íntimo puede proceder, como considera Lejeune, de hechos socioculturales: por ejemplo, es común regalar diarios a las niñas pero no a los niños. Además, entre las mujeres suele ser más común contarse intimidades y, en general, hablar y comunicarse más, por lo que va a ser frecuente también que entre amigas dejen que lean sus diarios. Los adolescentes tienden a escribir más para expresar sus sentimientos, de manera que se sienten liberados, ejerciendo el diario un efecto catártico y terapéutico. Se trata a menudo de responder, de alguna manera, a las preguntas de ¿quién soy? y ¿quién debo ser? (Lejeune, 2003: 141).

Sobre la cuestión de la temporalidad en la escritura del diario, Lejeune considera que es una escritura del día a día, una serie de huellas estructuradas por fechas que conforman nuestro diario íntimo. La base del diario es la fecha, que es el primer gesto que realiza el autor al escribir su diario, y tiene una importancia capital. Esto se une a la idea de la instantaneidad y autenticidad de la escritura: lo que escribimos permanece, no debemos volver atrás y modificarlo, no tenemos el derecho de cambiar nada; si lo hacemos, caemos en la autobiografía, perdiendo el concepto del diario.

El diario debe ser considerado como un manuscrito, donde las grafías, la inclusión de fotos, objetos y dibujos nos identifican e individualizan, quedando reflejada en nuestro diario nuestra personalidad y nuestra visión del mundo. Además, el diario se concibe como un lugar donde preservar nuestra memoria, donde el día de mañana podremos volver a reencontrarnos con elementos del pasado, y que servirá para reconstruir quiénes somos o quiénes y cómo hemos sido. La posibilidad de relectura del diario personal es lo que causa que lo conservemos, y esta relectura podrá realizarse tanto inmediatamente después de la escritura como años después en cualquier momento de nuestra vida, pudiendo llegar incluso a reescribir algunos de esos fragmentos (Lejeune, 2003: 125). Pero de la relectura puede también surgir el deseo de destrucción de alguna parte del diario; cuando esto sucede, 
se está yendo contra el propósito fundamental del diario: construir y conservar nuestras memorias, dejar nuestra huella, aunque no siempre: en ocasiones la relectura provoca que nos avergoncemos de nosotros mismos al observar nuestros sentimientos más íntimos escritos sobre un papel y, en un momento dado, impulsivamente, decidimos destruirlo (2003: 128).

El diario puede ser un confidente, un amigo al que mostramos nuestras emociones, pero sin renunciar a nuestra intimidad. Nos permite expresarnos con toda libertad, siendo un espacio ajeno a la presión social, constituyéndose como un refugio personal para uno mismo. Pero no solo eso, el diario es un espejo donde podemos mirarnos y un instrumento que nos sirve para conocernos a nosotros mismos, nos ofrece una imagen propia y además nos permite ver cómo hemos evolucionado, situándose como un espacio favorable para la construcción de nuestra imagen positiva al mismo tiempo que funciona como lugar de autorreflexión y examen crítico de nosotros mismos, de introspección y de exploración hacia nuestro yo interior. Lejeune establece, por otra parte, un posible origen de la escritura del diario íntimo en la redacción de las cartas familiares, como otra forma de interiorización. Podría tratase de una carta a sí mismo, como si de un amigo íntimo se tratase, donde expresamos nuestras confidencias.

Una de las características más importantes del diario podría ser la sinceridad, como manifestaron incluso los propios participantes del proyecto, pero no podríamos ser realmente sinceros si no tuviéramos claro que nadie va a leer lo que escribamos, por lo que el diario se fundamenta en el secreto y el rechazo a que otras personas puedan leer lo que escribimos. No hay interlocutor más discreto para expresar nuestros pensamientos más íntimos que uno mismo (Lejeune, 2003: 62).

Para escribir nuestro diario y que este sea verdaderamente privado, necesitamos una habitación para nosotros mismos, como afirmaba Virginia Woolf, un «refugio matricial», como afirma Béatrice Didier (1976: 72), aunque podemos escribir hasta en los lugares más multitudinarios gracias a la escritura en nuestro cuaderno, que podemos trasladar a cualquier sitio. Pero la escritura del diario es un acto íntimo y resulta desagradable ser observado mientras se escribe. La intimidad se presenta, por tanto, como uno de los requisitos para escribir el diario. Por ello, algunos adolescentes utilizan candados o esconden su diario a buen recaudo e incluso incluyen, en ocasiones, palabras dirigidas a ese supuesto posible lector indeseado. Esta intimidad se logra en ocasiones por la omisión de datos, por la escritura secreta o unas anotaciones descontextualizadas y complicadas de entender; y es que la verdadera intimidad solo se encuentra, paradójicamente, renunciando a la escritura en el diario (Lejeune, 2003: 116).

Otro problema en cuanto a la intimidad del diario se encuentra en el formato o soporte de escritura, puesto que, aunque generalmente se escoge un cuaderno o unas hojas sueltas, en los últimos años ha aumentado el número de diaristas que escriben en el ordenador, lo cual puede perjudicar a la privacidad del documento.

Otra preocupación para los diaristas, unida a la de la intimidad y privacidad, es dónde guardar el diario para garantizar que nadie pueda leerlo. El momento de la escritura, en cambio, varía notablemente en función de cada persona. 
El título del diario es asimismo una parte importante del mismo, al igual que las primeras líneas. El nombre del diarista suele aparecer al comienzo, dando cuenta de que se trata de un territorio privado. El título escogido suele ser, generalmente, «Mi diario», según afirma Lejeune (2003: 74), y así se pudo comprobar con los alumnos de la muestra. Se trata de un gesto de apropiación que resulta fundamental para el diario; todos los medios son buenos para expresar la afirmación de sí mismo: nombre, apellido, firma, iniciales del nombre, fotos, etc.

La disposición estética del título, así como del resto del diario, también va a tener relevancia en algunos casos, reflejándose una preocupación por parte del escritor por la caligrafía, el orden, el diseño, etc., que serán en cada caso como desee el propio diarista, puesto que pertenece a la libertad y la intimidad de cada uno de ellos.

Igualmente, podemos hablar de una «ceremonia del adiós» (Lejeune, 2003:122) cuando terminamos nuestro diario, que supone un momento de reflexión y meditación sobre lo que ha supuesto para nosotros y la ayuda que nos ha ofrecido, aunque en algunos casos esa ceremonia del adiós puede aparecer de algún modo al final de la entrada de cada día.

Otro factor que trata Lejeune es el del compromiso que adquiere el escritor con su diario. Cualquier hecho de nuestra vida puede ser el desencadenante de la escritura intimista, que va a propiciar la reflexión personal que sostiene el impulso inicial, como un pacto consigo mismo. El diarista es siempre quien decide cuándo comenzar o terminar su diario, por ejemplo, el día de su cumpleaños o el primer día del año.

La distribución y la disposición del espacio de la página o la inclusión de ilustraciones, dibujos u objetos en el diario son completamente personales, y aparecerán o no según el deseo del escritor, en función de si puede recordarle algún acontecimiento, expresar algún sentimiento, etc. El estilo utilizado, el uso de abreviaturas o de una redacción más o menos elaborada, serán también aspectos que dependerán de cada diarista.

En el diario cabe también la escritura sobre otras personas, aunque debemos concebirlo, fundamentalmente, como una herramienta para la reflexión sobre sí mismo.

La familia, el amor, la vida social o el trabajo (en este caso los estudios) van a ser los temas fundamentales que traten los diarios de los adolescentes, y en general los de todos los diaristas, como los aspectos más importantes en la vida del escritor. Así como podemos encontrar en los diarios referencias a viajes, acontecimientos cotidianos, y otros hechos acaecidos, también pueden aparecer descripciones de los sueños del diarista. Estas anotaciones pueden constituir un gran campo para el autoanálisis y psicoanálisis de la persona que escribe, puesto que puede revelar traumas infantiles o actuales. Escribir nuestros sueños puede ayudarnos a descubrir y liberarnos de nuestros propios misterios y miedos. Este ha sido el caso de una alumna de 1. ${ }^{\circ}$ de ESO de nuestra investigación, cuyo diario era un diario de sueños y se basaba continuamente en la idea del miedo a la muerte y a la pérdida de seres queridos, por lo que podemos observar cómo el diario sirve para expresar los miedos, traumas y sentimientos más íntimos. Y quizá puede ser terapéutico. 
La realización de la tarea del diario permitió a los informantes reflexionar sobre quiénes son y cómo son, puesto que es una manera de conocerse a sí mismos, de poderse definir y reflexionar sobre la construcción de su identidad y su personalidad. Durante la adolescencia, el niño se pregunta ¿qué/quién soy?, poniendo en tela de juicio los valores y actitudes de la pubertad y reflexionando sobre estos aspectos en el futuro (Reymond-Rivier, 1971: 165). El adolescente busca durante este periodo nuevos modelos e identificaciones, que va a buscar en su grupo de iguales, rehusando a sus padres. Esta búsqueda de la identidad preludia la colocación en su sitio de la personalidad, y la escritura del diario íntimo puede ayudar al adolescente en esta labor. Las dificultades de comunicación que sufre el adolescente en estos años provocan una constante comunicación angustiosa entre el otro y uno mismo, entre la identificación y la identidad; se produce una transformación profunda de la personalidad a la vez en su relación consigo mismo y en sus relaciones con los demás.

\section{Implementación de la investigación: perfil de los participantes}

Para la realización de este trabajo de investigación se seleccionó una muestra total de 46 alumnos, distribuidos entre $1 .^{\circ}$ de ESO (25 alumnos: 14 chicas y 11 chicos) y 3. ${ }^{\circ}$ de ESO (21 alumnos: 12 chicas y 9 chicos), pertenecientes al IES Luis Buñuel de Zaragoza. Se escogieron estos dos cursos para observar sus divergencias y similitudes en cuanto a la conformación de la propia personalidad e identidad, al entenderse ambos como la manifestación de, por un lado, el comienzo de la Educación Secundaria, con los cambios y novedades que ello conlleva en el alumno ( $1 .^{\circ}$ de ESO) y el curso en el que más claramente estalla la personalidad y el carácter del adolescente y que es el que se presta a una mayor riqueza de actitudes autorreflexivas y de autoconocimiento, así como de conformación de unas señas de identidad concretas, debido a sus características evolutivas de desarrollo ( $3{ }^{\circ}$ de ESO).

Los resultados del estudio muestran que se confirman teorías como las de Lejeune (2003: 150), quien afirma que las referencias a la familia es uno de los aspectos que más aparece en el diario personal de un adolescente de $1 .^{\circ}$ de ESO (12 años), mientras que en los diarios de los alumnos de $3 .^{\circ}$ de ESO (15 años) los temas amorosos y la amistad cobran un mayor protagonismo. Lejeune (2003: 143) explica que durante la adolescencia aparece el amor de una forma reservada para nosotros mismos, privada, secreta, que solo se comparte con nuestro diario y que tiene un efecto terapéutico ante las dudas o el desamor. Se trata de un momento vital en el que todo está impregnado de los sentimientos afectivos y se presenta el amor y la amistad como una forma de comprensión del mundo, sobre todo entre las mujeres, quienes adquieren «una jerarquía de valores afectivos» en este momento (Piaget, 1990: 91).

\section{Resultados del análisis cualitativo de los diarios}

El aspecto lingüístico en el que más se observa la manifestación expresa de la intimidad y de la subjetividad del autor del diario es el léxico. La subjetividad del yo autor del diario es la marca que decide la selección léxica en el discurso. La elección de una sufijación apreciativa (por ejemplo, sabadazo) y, especialmente, de los adjetivos calificativos que se emplean reflejan indirectamente una 
valoración de los hechos que se narran, es decir, no se transmite meramente una información sino que dicha información lleva implícita una huella personal, subjetiva: la mirada íntima del autor del diario. Por ello, en el análisis de los resultados nos vamos a centrar aquí en aquellos rasgos que transmiten datos o que describen situaciones subjetivamente.

En primer lugar, vamos a hacer algunas anotaciones acerca de ciertos rasgos gramaticales que se asocian a la subjetividad. En todos los casos, se utiliza la primera persona del singular para narrar los hechos, pero hay que destacar que, mientras que se utiliza esta persona para expresar las situaciones positivas, se combina con el uso de la forma plural para las negativas. Esto es indicativo de la manera que tiene el adolescente de afrontar las situaciones que no le son favorables como una cuestión que no le incumbe exclusivamente a sí mismo sino también a otras personas, por lo que se crea una sensación de alivio de la responsabilidad de tales situaciones.

En segundo lugar, encontramos el uso de la repetición del adjetivo, como en gran gran sábado (alumna de 3..$^{\circ} \mathrm{ESO}$ ), lo que da muestra del deseo de los adolescentes por resaltar aquellos elementos que consideran más importantes o más felices para ellos, lo cual no deja de ser una perspectiva particular de cada alumno.

También encontramos muy frecuentemente muestras de cariño de algunas chicas hacia sus amigas, junto con la expresión de los sentimientos y de la afectividad. Esto no es tan frecuente entre los chicos (solo hay un caso en el que un alumno da muestras de llanto), aunque también aparecen algunos ejemplos de muestra de sentimientos que, generalmente en el caso masculino, se dirigen hacia el aburrimiento, la indignación o la alegría.

Por otra parte, centrándonos más específicamente en el léxico extraído de los diarios, a partir del estudio del léxico disponible en los adolescentes de $1 .^{\circ}$ y $3 .^{\circ}$ de ESO se obtuvieron datos interesantes acerca del uso de voces con un valor negativo y voces con un valor positivo o no marcado.

Se presentan a continuación unas tablas que sintetizan las voces con valor negativo y con valor positivo registradas en el estudio del léxico de ambas edades:

Tabla 1: Voces con un valor negativo

\begin{tabular}{|c|c|c|c|c|c|c|c|}
\hline \multicolumn{4}{|c|}{$10^{\circ} \mathrm{ESO}$} & \multicolumn{4}{|c|}{$3^{\circ} \mathrm{ESO}$} \\
\hline \multicolumn{2}{|c|}{ ALUMNOS } & \multicolumn{2}{|c|}{ ALUMNAS } & \multicolumn{2}{|c|}{ ALUMNOS } & \multicolumn{2}{|c|}{ ALUMNAS } \\
\hline $\mathbf{N}^{\mathbf{0}}$ & VOZ & VOZ & $\mathbf{N}^{0}$ & $\mathbf{N}^{\mathbf{0}}$ & VOZ & VOZ & $\mathbf{N}^{0}$ \\
\hline 22 & \multicolumn{2}{|c|}{$\begin{array}{c}\text { Aburrido/a } \\
\text { "Aburrición" (1 alumna) }\end{array}$} & 16 & 7 & \multicolumn{2}{|c|}{ Aburrido } & 9 \\
\hline 3 & $\begin{array}{l}\text { No tener } \\
\text { ganas }\end{array}$ & & & 2 & $\begin{array}{l}\text { No tener } \\
\text { ganas }\end{array}$ & & \\
\hline 1 & Desmotivado & & & & & & \\
\hline 1 & Estresado & & & 1 & Ajetreado & Estresante & 2 \\
\hline 1 & Agobiado & & & & & Agobiada & 1 \\
\hline & & Tontadas & 1 & & & & \\
\hline & & $\begin{array}{l}\text { "No podía } \\
\text { con mi } \\
\text { alma" }\end{array}$ & 1 & & & & \\
\hline
\end{tabular}


Tropelias. Revista de Teoría de la Literatura y Literatura Comparada, 31 (2019)

Análisis del discurso autoficcional en los adolescentes: la subjetividad a través del diario

\begin{tabular}{|c|c|c|c|c|c|c|c|}
\hline & & Liada & 1 & & & & \\
\hline & & $\begin{array}{l}\text { "Paliza } \\
\text { tremenda" }\end{array}$ & 1 & & & & \\
\hline 2 & \multicolumn{2}{|c|}{ Difícil, "complicao" } & 2 & 2 & $\begin{array}{l}\text { Difícil (1), } \\
\text { Guapo (1) }\end{array}$ & & \\
\hline \multirow[t]{12}{*}{1} & "Reventao" & Agotada & 1 & 1 & \multicolumn{2}{|c|}{ Agotado/a } & 1 \\
\hline & & & & 1 & "Petao" & & \\
\hline & & Horror & 1 & & & & 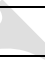 \\
\hline & & Berreo & 1 & & & 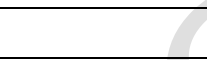 & \\
\hline & & $\begin{array}{c}\text { Echar la } \\
\text { bronca }\end{array}$ & 3 & & & & \\
\hline & & Cansancio & 1 & 5 & \multicolumn{2}{|c|}{ Cansado/a } & 6 \\
\hline & & & & & & $\begin{array}{l}\text { "Estar } \\
\text { muerta" }\end{array}$ & 3 \\
\hline & & $\begin{array}{c}\text { Marihuana, } \\
\text { droga }\end{array}$ & 1 & & 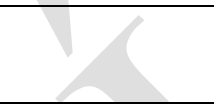 & & \\
\hline & & $\begin{array}{l}\text { "No me } \\
\text { gusta nada" }\end{array}$ & 1 & 1 & $\begin{array}{l}\text { "No me } \\
\text { gusta" }\end{array}$ & & \\
\hline & & Miedo & 4 & $\bar{z}$ & & 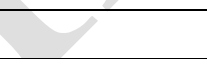 & \\
\hline & & Pesadilla & 1 & 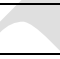 & & 5 & \\
\hline & & Muerte & 1 & & & & \\
\hline 1 & "Coñaso" & & 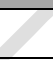 & 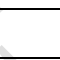 & 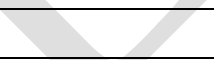 & & \\
\hline 2 & Rollo & & & 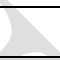 & 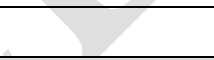 & & \\
\hline 1 & Mierda & & & 4 & Mierda & & \\
\hline 1 & $\begin{array}{l}\text { Dejarme } \\
\text { tranquilo }\end{array}$ & & & & & & \\
\hline \multirow[t]{14}{*}{1} & & 0 & 2 & 1 & Puta & & \\
\hline & & $\begin{array}{l}\text { Poner } \\
\text { enferma }\end{array}$ & 1 & 1 & $\begin{array}{c}\text { Saber muy } \\
\text { malo }\end{array}$ & & \\
\hline & & & & 9 & \multicolumn{2}{|c|}{ Nervioso/a } & 3 \\
\hline & & & & 1 & $\begin{array}{l}\text { No ser gran } \\
\text { cosa }\end{array}$ & $\begin{array}{c}\text { Nada fuera } \\
\text { de lo } \\
\text { normal }\end{array}$ & 1 \\
\hline & & & & 1 & $\begin{array}{c}\text { "Me } \\
\text { deprime" }\end{array}$ & & \\
\hline & & & & 2 & \multicolumn{2}{|c|}{ Triste } & 3 \\
\hline & 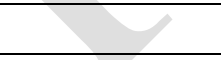 & & & 1 & \multicolumn{2}{|c|}{ Cabreado/a } & 1 \\
\hline & 2 & & & 1 & Rabia & & \\
\hline & & & & 1 & \multicolumn{2}{|c|}{ Odiar } & 1 \\
\hline & 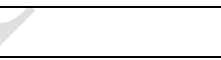 & & & 1 & Pésimo & & \\
\hline & & & & 1 & Muy duro & & \\
\hline & & & & 1 & Decepción & & \\
\hline & & & & 2 & $\begin{array}{c}\text { "Llorera", } \\
\text { "llorar a } \\
\text { moco } \\
\text { tendido" }\end{array}$ & & \\
\hline & & & & 1 & Molesto & Pesada & 1 \\
\hline
\end{tabular}




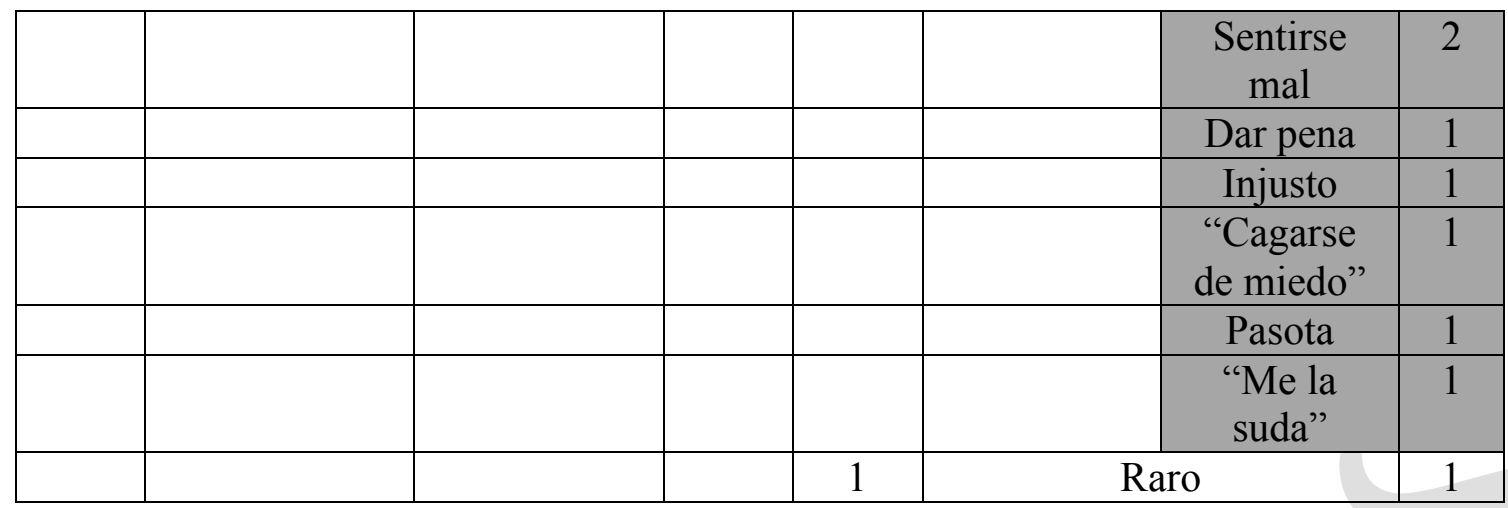

Tabla 2: Voces con un valor positivo

\begin{tabular}{|c|c|c|c|c|c|c|c|}
\hline \multicolumn{4}{|c|}{$1 .^{\circ}$ ESO } & \multicolumn{4}{|c|}{ 3. ${ }^{\circ}$ ESO } \\
\hline \multicolumn{2}{|r|}{ ALUMNOS } & \multicolumn{2}{|c|}{ ALUMNAS } & \multicolumn{2}{|c|}{ ALUMNOS } & \multicolumn{2}{|c|}{ ALUMNAS } \\
\hline $\mathrm{N}^{0}$ & VOZ & VOZ & $\mathrm{N}^{0}$ & $\mathrm{~N}^{0}$ & VOZ & VOZ & $\mathrm{N}^{\mathbf{0}}$ \\
\hline 1 & Pasarlo muy bien & & & 6 & \multicolumn{2}{|c|}{ Pasarlo muy bien } & 3 \\
\hline 1 & $\begin{array}{l}\text { Extranjerismos: } \\
\text { record }\end{array}$ & $\begin{array}{l}\text { Extranjeris- } \\
\text { mos: } \\
\text { Happy; } \\
\text { don't worry, } \\
\text { be happy; } \\
\text { happily; } \\
\text { croissan }\end{array}$ & 5 & 1 & $\begin{array}{l}\text { Extranjeris- } \\
\text { mos: } \\
\text { online }\end{array}$ & $\begin{array}{l}\text { Extranjeris } \\
\text { mos: } \\
\text { Hello; ciao; } \\
\text { konichiwa; } \\
\text { cosplayer }\end{array}$ & 10 \\
\hline 1 & \multicolumn{2}{|c|}{ Especial } & 1 & & $D$ & & \\
\hline 1 & Nada especial & 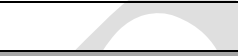 & & 2 & \multicolumn{2}{|c|}{ Nada importante } & 1 \\
\hline 1 & Disfrutar & $\begin{array}{l}\text { Divertir, } \\
\text { "diver" }\end{array}$ & 6 & 1 & \multicolumn{2}{|c|}{ Divertido } & 1 \\
\hline & & Entretenido & 1 & 1 & Entretenido & & \\
\hline 3 & \multicolumn{2}{|c|}{ Genial } & 5 & & & Genial & 1 \\
\hline & & Reflexionar & 1 & 1 & Reflexionar & & \\
\hline & & Orgullosa & 1 & & & & \\
\hline & & Gran día & 1 & & & & \\
\hline & & $\begin{array}{l}\text { Feliz, } \\
\text { contenta, } \\
\text { "happy" }\end{array}$ & 5 & 1 & \multicolumn{2}{|c|}{ Contento/a } & 1 \\
\hline 8 & \multicolumn{2}{|c|}{$\begin{array}{l}\text { Rutina: "como siempre", "lo } \\
\text { mismo de siempre", "como } \\
\text { todos los días" }\end{array}$} & 1 & 10 & \multicolumn{2}{|c|}{$\begin{array}{l}\text { "lo de siempre", "para } \\
\text { variar", "me canso ya de } \\
\text { esta rutina" }\end{array}$} & 3 \\
\hline 1 & Mola & & & & & & \\
\hline 1 & \multicolumn{2}{|c|}{ Interesante } & 1 & 2 & \multicolumn{2}{|c|}{ Interesante } & 7 \\
\hline \multirow[t]{6}{*}{2} & \multicolumn{2}{|c|}{ Nada interesante } & 7 & 1 & \multicolumn{2}{|c|}{ Nada interesante } & 6 \\
\hline & & $\begin{array}{c}\text { DPM (De } \\
\text { Puta Madre) }\end{array}$ & 2 & & & & \\
\hline & & Mogollón & 1 & 1 & Mogollón & & \\
\hline & & & & 1 & \multicolumn{2}{|c|}{ Un montón } & 6 \\
\hline & & "como dios" & 1 & & & & \\
\hline & & Experta & 1 & & & & \\
\hline
\end{tabular}


Tropelías. Revista de Teoría de la Literatura y Literatura Comparada, 31 (2019) Análisis del discurso autoficcional en los adolescentes: la subjetividad a través del diario

\begin{tabular}{|c|c|c|c|c|c|c|c|}
\hline & & "Chuches" & 1 & & & & \\
\hline & & Encantar & 1 & 1 & \multicolumn{2}{|c|}{ Gustar mucho } & 1 \\
\hline & & Alucinante & 1 & & & & \\
\hline & & Paridas & 1 & & & & \\
\hline & & $\begin{array}{l}\text { Aragonesis- } \\
\text { mos: } \\
\text { majo, } \\
\text { charrar, } \\
\text { Cipotegato }\end{array}$ & 3 & 1 & $\begin{array}{l}\text { Aragonesis } \\
\text { mos: } \\
\text { fuemos }\end{array}$ & $\begin{array}{l}\text { Aragonesis- } \\
\text { mos: } \\
\text { majos, } \\
\text { jornaicas, } \\
\text { familica }\end{array}$ & 5 \\
\hline & & Sueños & 5 & & & & 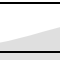 \\
\hline & & Pensativa & 1 & & & 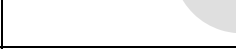 & 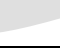 \\
\hline & & & & 1 & Intimidad & & \\
\hline & & & & 2 & $\begin{array}{c}\text { Emocionan- } \\
\text { te }\end{array}$ & & $T$ \\
\hline & & & & 3 & \multicolumn{2}{|c|}{ Alegrar, alegría } & 1 \\
\hline & & & & 4 & \multicolumn{2}{|c|}{$\begin{array}{c}\text { Descansar, dar una } \\
\text { cabezada }\end{array}$} & 1 \\
\hline & & & & 2 & Relajado & & \\
\hline & & & & 1 & Tranquilo & 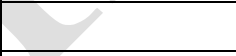 & \\
\hline & & & & 1 & Especial & 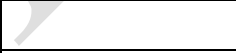 & \\
\hline & & & & 1 & Bonito & & \\
\hline & & & & 2 & Desestresar & & \\
\hline & & & & 1 & Relax & & \\
\hline & & & & 1 & Optimista & & \\
\hline & & & & 1 & \multicolumn{2}{|c|}{$\begin{array}{c}\text { "no se me ocurre qué más } \\
\text { decir", "no sé qué más } \\
\text { poner" }\end{array}$} & 4 \\
\hline & & & & & & Tener ganas & 6 \\
\hline & & & & 1 & \multicolumn{2}{|c|}{$\begin{array}{l}\text { Reírse mucho, "echarse } \\
\text { unas risas" }\end{array}$} & 2 \\
\hline & & & & 1 & Inspirarme & & \\
\hline & & & & 1 & \multicolumn{2}{|c|}{ Obligación } & 2 \\
\hline & & & & 3 & $\begin{array}{l}\text { Resaca, } \\
\text { "pillarla } \\
\text { bien" }\end{array}$ & & \\
\hline & & & & 1 & $\begin{array}{c}\text { Caer } \\
\text { [asignatura] }\end{array}$ & & \\
\hline & $y$ & & & 1 & Llamativo & & \\
\hline & 2 & & & 1 & "a tope" & & \\
\hline & & & & 1 & "pedazo" & & \\
\hline & Y & & & & & Confianza & 1 \\
\hline & $P$ & & & & & Enganchada & 1 \\
\hline & & & & & & $\begin{array}{c}\begin{array}{c}\text { Estar a } \\
\text { gusto }\end{array} \\
\end{array}$ & 1 \\
\hline & & & & & & Adorada & 1 \\
\hline & & & & & & $\begin{array}{l}\text { "sabadazo", } \\
\text { gran sábado }\end{array}$ & 2 \\
\hline
\end{tabular}




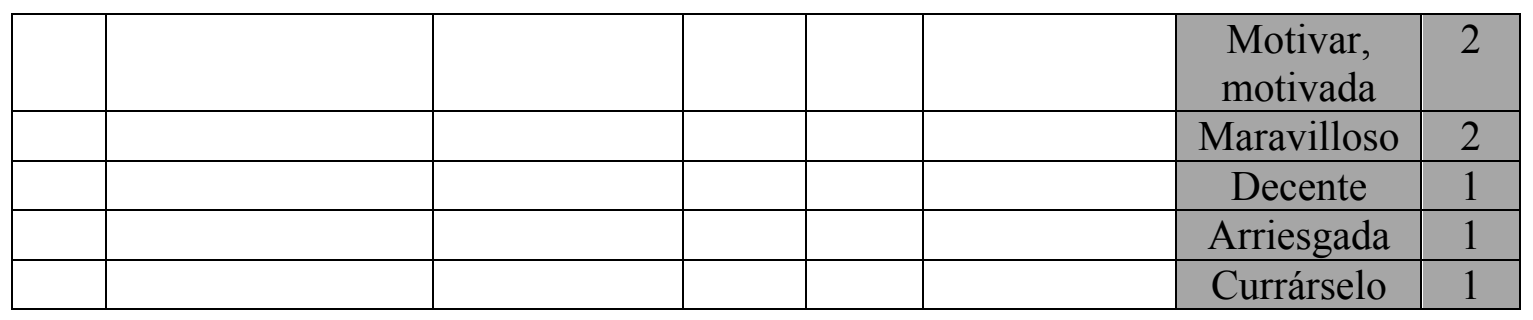

Algunos resultados significativos que se extraen a partir del análisis de los textos elaborados por los propios alumnos, en relación con el léxico que hemos apuntado más arriba, se detallan a continuación:

- La palabra más recurrente en los diarios ha sido aburrido/a o aburrimiento (se recoge un total de 54 veces: 38 en $1 .^{\circ}$ ESO y 16 en $3 .^{\circ}$ ESO).

- Un importante número de alumnos se encuentra en situación de agotamiento o estrés, registrándose voces relacionadas con estos estados en 35 ocasiones, entre ellas: desmotivado, estresado, agobiado/a, ajetreado, estresante, reventao, petao, cansado/a, cansancio, etc.

- Las mujeres emplean más expresiones vagas: un montón, bueno, mogollón, etc.

- Encontramos numerosas voces tanto con un valor positivo como negativo, sin predominio claro de unas u otras en cada curso o sexo.

- En cuanto al léxico negativo, se producen pocas coincidencias entre sexos en $1 .^{\circ} \mathrm{ESO}$, aunque las similitudes son más frecuentes en los alumnos de $3 .^{\circ}$ ESO.

- En los términos positivos es donde aparecen los extranjerismos (hasta en 17 ocasiones, predominando claramente en las mujeres), resultando más numeroso el número de anglicismos: happy, don't worry, happily, hello, cosplayer.

- En general, los alumnos expresan positivamente que lo pasan bien, se divierten y están contentos. Sobre este campo semántico encontramos unas 20 entradas relacionadas.

- Los alumnos de $3 .^{\circ}$ ESO tienen una visión de la vida como algo más rutinario y repetitivo, que desean cambiar, aunque esta idea aparece en ambos cursos. A diferencia del otro grupo, en tercero se habla de rutina hasta en 21 ocasiones y suele ir unido este término al del cansancio.

- En ambos cursos y sexos, las entradas del diario varían notablemente según se trate de días laborables o festivos. Así, las voces positivas se perciben mejor durante el fin de semana, momento en el que se describen más situaciones de ocio y con amigos.

- Si bien aparecen muchos términos generalmente en torno al campo léxico del agotamiento y estrés, los chicos de $3 .^{\circ}$ de ESO son los únicos que incluyen voces en torno a la relajación y el descanso, como tranquilo, relajado, desestresar, relax, descansar.

- En general, los usos léxicos no reflejan una preferencia por los términos más adecuados o por cultismos, sino que la escritura es espontánea y poco cuidada, independientemente de las variables edad, sexo y nacionalidad.

- Encontramos, asimismo, algunos aragonesismos que dan muestra de la identidad aragonesa de estos alumnos hasta en 9 ocasiones (-ico, majo, charrar, fuemos, Cipotegato). 
- Finalmente, en general se aprecia en el léxico utilizado por los adolescentes un mayor optimismo y felicidad entre los alumnos de $3 .^{\circ} \mathrm{ESO}$ frente a los de $1 .^{\circ} \mathrm{ESO}$, como preveíamos a partir de la teoría de Lejeune. Se utilizan términos y expresiones como: a tope, pedazo de..., estar a gusto, motivada, genial, maravilloso, bonito, especial, optimista, alegría, emocionante, feliz, contento, mola, etc.

\section{Conclusiones sobre la subjetividad e identidad en la escritura del diario de los adolescentes}

Como vemos a partir de los resultados extraídos del análisis del corpus, se deduce que los adolescentes se definen a partir de lo que los demás dicen de ellos y que las palabras que utilizan para designarse a sí mismos forman parte de la cotidianidad expresada en los lazos que entablan. Como afirman Gómez y Carrasco (2012: 65):

Existe una designación que determina la identidad, la cual está constituida de los significantes sociales y culturales que emergen [...] Esa identidad es la significación paulatina de hechos históricos y actuales que operan en la subjetividad del joven adolescente.

La concepción de la identidad, expresada a través de la subjetividad en el discurso de los jóvenes, se manifiesta lingüísticamente en los diarios a partir de la historia de cada uno y de la manera en que, a través del lenguaje, los adolescentes, como grupo social, logran enunciar sus experiencias de forma particular.

El análisis del corpus léxico que se extrajo de los diarios íntimos de estos grupos de adolescentes nos permite concluir que la escritura de este tipo de textos es significativa para los propios adolescentes-autores, ya que sirve para manifestar su yo interior y su forma particular de entender el mundo y de situarse dentro de un grupo o estrato social. El tipo de palabras que selecciona el autor del diario no es aleatorio. Las voces que empleamos para hablar sobre nuestro mundo y con nosotros mismos reflejan una parte del yo íntimo que mostramos en mayor o menor medida al exterior. En el mundo del adolescente, que aquí nos ocupa, todavía es mayor la sensación de pertenencia a un grupo y la necesidad de mostrarlo también a través de una manera específica de expresarse y comunicarse.

La reiterada aparición de voces relacionadas con el aburrimiento, el estrés o la efusividad ante los acontecimientos es indicativa de la forma subjetiva en que los hechos y las circunstancias que le rodean son percibidas y narradas por el adolescente.

Como comentábamos al principio, el mero hecho de utilizar los adjetivos calificativos para calificar un acontecimiento o a una persona, el hecho de seleccionar uno u otro y de emplear una palabra determinada que va a aportar una significación añadida y particular al hecho que estamos describiendo hace que se desdibuje la posibilidad de objetividad en el discurso y se traslade, casi automáticamente, a un discurso subjetivo, como no puede ser de otra forma al tratarse de un texto que traslada nuestro mundo privado e íntimo al papel, pero que lleva consigo inherentemente la marca personal de ese yo responsable de las palabras que fluyen, ya que lo hacen desde un interior sin vetos, en un texto que no tiene ningún otro destinatario sino uno mismo. 
La subjetividad que demuestra la escritura del diario se refleja en las diversas formas que cada informante tiene de expresarse y de seleccionar qué acontecimientos narra y cómo, aunque, como vemos, en el caso de los adolescentes se trata de una subjetividad unida a un sentimiento fuerte de identidad al grupo que genera unos resultados con una alta coincidencia léxica, que produce voces utilizadas con una mayor frecuencia respecto a las otras, y que no puede ser casual, sino el resultado de ese sentimiento de pertenencia al grupo, un grupo que posee una percepción subjetiva de carácter bastante global de la realidad de la vida de un adolescente, puesto que se limita, casi siempre, a una serie de situaciones y contextos cerrada, que les produce sentimientos y emociones similares.

\section{Referencias bibliográficas}

Alberca Serrano, M. (2000): La escritura invisible. Oiartzun, Sendoa.

CORRAdO, D. (2000): Le journal intime en Espagne. Aix en Provence, Université de Provence.

CORTÉS TORRES, J. E. (2017): Construcción de la identidad narrativa a través del texto autobiográfico en jóvenes privados de la libertad [en línea]. Bogotá, Universidad Distrital Francisco José de Caldas (Trabajo Fin de Máster). Disponible en: http://repository.udistrital.edu.co/bitstream/11349/6537/1/CortesTorresJoseEduardo2017.PDF.. pdf

DIDIER, B. (1976): Le journal intime. París, Presses Universitaires de France.

Elliot, J. (2000): La investigación-acción en educación [en línea]. Madrid, Morata. Disponible en: http://www.salgadoanoni.cl/wordpressjs/wp-content/uploads/2010/02/10ELLIOT-Jhon-Cap-1-y$\underline{5 . p d f}$

FERNÁNDEZ, G. (2007): «Bajtín y Vigotsky: La experiencia social en la producción de sentido. Algunas prioridades para enseñar literatura», en AdVersuS, Año IV,- No 8-9, abril-agosto 2007. Disponible en: http://www.adversus.org/indice/nro8-9/articulos/articulo fernandez.htm

FIERro, A. (1997): «La construcción de la identidad personal», en MARTÍ y ONRUBIA (Coord.), Psicología del desarrollo: el mundo del adolescente. Barcelona, Horsori (pp. 73-94).

GómEZ Y CARRASCO (2012): «Identidad y discurso en jóvenes adolescentes del Colegio Universidad Cooperativa de Colombia», en Pensando Psicología, 8, Número 15, Colombia,Editorial Universidad Cooperativa de Colombia, pp. 54-73.

LeJeune, P. (1971): L'autobiographie en France. París, Armand Colin.

(1975): «El pacto autobiográfico», en Suplementos Anthropos 48, Barcelona, Siglo XXI, pp. 47-61.

(1996): «La práctica del diario personal: una investigación (1986-1996)», en Revista de Occidente, Número 182-183, Madrid, Fundación José Ortega y Gasset-Gregorio Marañón, pp. $55-71$.

(1998): Pour l'autobiographie. París, Seuil. 
(2003): Un journal à soi. Histoire d'une pratique. París, Textuel.

«Autopacte. Site proposé par Philippe Lejeune» [en línea]. Disponible en:

http://www.autopacte.org/

Piaget, J. (1990): Seis estudios de psicología. Barcelona, Ariel.

REYMOND-RIVIER, B. (1971): El desarrollo social del niño y del adolescente. Barcelona, Herder.

TORres CARrillo, A. (2006): «Subjetividad y sujeto: perspectivas para abordar lo social y lo educativo», en Revista Colombiana de Educación, Número 50, Colombia, Editorial Universidad Pedagógica Nacional, pp. 86-103.

VygostKy, L. (1986) [1995]: Pensamiento y Lenguaje. Barcelona, Paidós. 